\title{
Commentary on neuromyelitis optica associated with painful paroxysmal dystonia: case report and literature review
}

\author{
Sergio Alejandro Rodríguez-Quiroga • \\ Luz Abaroa • Tomoko Arakaki • Nélida S. Garretto • \\ Andrés M. Villa
}

Received: 23 September 2014/ Accepted: 29 October 2014/Published online: 9 November 2014

(C) Belgian Neurological Society 2014

\section{To the Editor}

Dr Bălaşa has provided an interesting description of the presence of paroxysmal dystonia in a patient with neuromyelitis optica [1]. The paroxysmal dystonia, also called Tonic Spasms, was the most frequent movement disorder described in patients with multiple sclerosis [2]. However, based on recent studies, it is stated that paroxysmal dystonia could be more commonly seen in patients with neuromyelitis optica spectrum disorders compared to patients with multiple sclerosis. This has led to consider that transverse myelitis, typically longitudinally extensive (more than 3 vertebral segments), followed by tonic spasms is a signature clinical feature of neuromyelitis optica [3].

\section{S. A. Rodríguez-Quiroga $(\bowtie) \cdot$ L. Abaroa · T. Arakaki}

N. S. Garretto

Movement Disorders Section, Neurology, Hospital J.M. Ramos

Mejía, Urquiza \#609, CABA, 1221 Buenos Aires, Argentina

e-mail: sergiorodriguez@dr.com

L. Abaroa

e-mail: luzabaroa@hotmail.com

T. Arakaki

e-mail: tomokookinawa@hotmail.com

N. S. Garretto

e-mail: nsgarretto@gmail.com

S. A. Rodríguez-Quiroga · L. Abaroa · T. Arakaki .

N. S. Garretto - A. M. Villa

University Centre of Neurology, Faculty of Medicine, Buenos

Aires University, Buenos Aires, Argentina

e-mail: avilla@fmed.uba.ar

A. M. Villa

Neuroinmunology Section, Neurology, Hospital J.M. Ramos

Mejía, Buenos Aires, Argentina
In our experience, in a recent study, we found the presence of paroxysmal dystonia in $95 \%$ (18 of 19) of a group of patients with clinical and radiological criteria for NMO spectrum disorders [4]. The principal features of our patients were the occurrence of a somesthetic aura associated with the paroxysmal dystonia in 18 of 19 patients, as well as the worsening of the movement disorders during the acute phases of the disease. Almost all patients had a dramatic response to the use of carbamazepine or acetazolamide, as seen in the case described by Dr Bălaşa and consistent with previous reports $[2,5]$.

We believe that one of the reasons for an increasing incidence of paroxysmal dystonia in our NMO patients could be explained due to the fact that we employed a structured questionnaire to find signs and symptoms that suggested the presence of paroxysmal dystonia and because of a long follow-up period in most of the evaluated subjects.

Based on our experience, we support the hypothesis that paroxysmal dystonia could be a common movement disorder in patients with neuromyelitis optica. The recognition of this clinical picture is relevant because we can offer a medical therapy that could relieve the symptoms.

Conflict of interest All the authors state that there is no conflict of interests regarding the publication of this article.

\section{References}

1. Balasa R, et al. (2014) Neuromyelitis optica associated with painful paroxysmal dystonia: case report and literature review. Acta Neurol Belg

2. Waubant E et al (2001) Paroxysmal dystonia (tonic spasm) in multiple sclerosis. Neurology 57(12):2320-2321

3. Flanagan EP, Weinshenker BG (2014) Neuromyelitis optica spectrum disorders. Curr Neurol Neurosci Rep 14(9):483 
4. Abaroa L et al (2013) Tonic spasms are a common clinical manifestation in patients with neuromyelitis optica. Arq Neuropsiquiatr 71(5):280-283
5. Spissu A et al (1999) Anatomic correlates of painful tonic spasms in multiple sclerosis. Mov Disord 14(2): $331-335$ 